\title{
Introduction to Special Issue: African Rock Art and Digital Practice
}

\author{
Helen Anderson (D) • Jorge de Torres • Elizabeth Galvin
}

Published online: 6 July 2018

C) Springer Science+Business Media, LLC, part of Springer Nature 2018

The use and spread of digital technology in the last two decades has changed the way that researchers document, collect, store, collaborate and engage the public with Africa's rock art. The increasing number of available digital resources is providing scholars with innovative ways to study, record and disseminate information about the continent's rock art heritage. Despite the diversity of styles, locations and states of preservation, the technology used has wide applicability across the continent. From photo enhancement software to easily portable specialised tablets, to mobile apps and social media, the ability to record, manage and present rock art research is ever increasing. However, this explosion of digital resources has also brought about increasing challenges relating to digital storage, training, curatorship and resource availability, especially in a continent where access to the Internet is still far from satisfactory.

This special issue of African Archaeological Review entitled "African Rock Art and Digital Practice" was borne out of a conference held at the British Museum on the 4th and 5th of November 2016, entitled 'African Rock Art: Research, Digital Outputs and Heritage

\footnotetext{
H. Anderson $(\bowtie) \cdot J$. de Torres $\cdot$ E. Galvin

Department of Africa, Oceania and the Americas, The British Museum, Great Russell Street, London WC1B3DG, UK e-mail: HAnderson@britishmusem.org

J. de Torres

e-mail: JdeTorres@britishmuseum.org

E. Galvin

e-mail: EGalvin@britishmuseum.org
}

Management'. It was initiated and organised by the African Rock Art Image Project (britishmuseum. org/africanrockart), a five-year project devised to register and disseminate c. 24,000 digital images of Africa's rock art, donated by the Trust for African Rock Art (TARA). The aim of the conference was to act as a forum to discuss the use of digital technology techniques and to encourage collaboration laterally across the continent. It brought together over 100 scholars from throughout the world to discuss the role of the digital in fieldwork, community engagement and database management and to consider some of the challenges that the study and preservation of African rock art will face in the next decades, whilst adapting to the pace imposed by the digital revolution. This issue has been organised along the lines of the conference whereby papers engage with three particular themes: current fieldwork and digital techniques for the recording and study of rock art, rock art and community engagement and catalogues and preservation of rock art. The contributions in this issue highlight these key areas where digital technology is being applied in rock art research and outreach, but also emphasise its wide geographic implementation and the variety and complexity of scenarios where these technologies are applied.

Firstly, digital technology is changing the practical applications in current fieldwork for the recording and study of rock art. The documentation of rock art has a rich tradition that spans more than a century with new methods being continuously tried and tested. Tracing was the traditional method of recording rock art panels and motifs, but in more recent years, digital methods of 
documentation have begun to supplement and enhance the recording process. Photo enhancement software allows insights into imagery that is either obscured or invisible to the naked eye, providing a greatly increased data set for researchers to study within theoretical frameworks, as Hollmann proposes for the study of bee depictions in southern Africa. From a different perspective, tablets and small portable technologies are changing how rock art is recorded in order to generate more accurate and efficient copies of inscriptions and rock art, augmenting earlier techniques (Urcia, Darnell, and Darnell). In addition, digital technology can play a vital role in areas where the need to document rock art becomes increasingly urgent due to social, economic and political threats in many areas of Africa, including places as relevant as the Dakhlek Oasis in Egypt (Polkowski).

Whilst technology is changing how fieldwork is conducted, it is also creating both new opportunities and challenges with community engagement. Including the local community in not only the protection of rock art sites but in their research and assessment has been facilitated by the development of digital technologies. As Deacon, Wiltshire, and du Plessis argue, digital programs and outputs, for example, mobile apps to be used in the field by volunteers and heritage professionals, provide valuable information that can be used in conservation and management plans such as those implemented in the Cederberg Mountains, South Africa. Similarly, the ease of use of digital technologies and enhanced communication can change the way that rock art imagery can be collected, involving local communities in the collecting process and training local people in archaeological practice and heritage management (Challis). By using existing familiar technologies in the collection and documentation of oral histories of local elders, and by building upon established and sustained social structures, as Namono presents, communities can be active agents in their own rock art heritage tourism initiatives.

However, overcoming the digital divide can be a major challenge when focusing on community engagement. Although the introduction of digital devices and internet connectivity is quickly expanding in Africa, it is still often out of reach for many local communities, especially in rural areas (Gallinaro). Additionally, where equipment is available, archaeology is not always the number one priority of community groups. This can be a major challenge for setting up training programs, especially in areas of conflict. A case study of Western Sahara, presented by Quesada, is an example of the difficult balance to be achieved between rock art protection, local training, and the availability of technological resources in a conflictive political context.

Finally, a major challenge in rock art research lies in the volume of data that is being created and the systems and processes by which this information, in a variety of formats, should be catalogued, presented and disseminated online. The immense number of digital photographs being created, and the opportunities and challenges presented in creating catalogues is a major undertaking by many institutions such as the African Archaeology Archive of Cologne (Lenssen-Erz, Fäder, Jesse, and Wilmeroth). However, and as di Lernia describes in his analysis of the future of the Saharan rock art, one of the criticisms of online rock art databases is the absence of contextual information or theoretical approaches, as well as the extent to which local communities are able to exploit these digital resources. As more institutions store rock art images and make them accessible online, it becomes incumbent upon them to be critically reflective of curation practices, digital preservation and audience engagement, locally and globally. In that sense, the African Rock Art Image project, based at the British Museum, represents a major initiative to present a collection of African rock art in a way which is at the same time comprehensive to scholarship and accessible to the general public (Anderson, Galvin, and de Torres).

The role of digital technologies in rock art research is a continuously changing and developing environment in which to work, and the future of best practice has to lie in our capacity and willingness to share data and working practices, both positive and negative. By focusing on these three key themes - fieldwork, community engagement and digital preservation - this special issue discusses major initiatives and challenges, and hopes to raise new approaches and applications of technology in the study of African rock art. 